\title{
Household air pollution in South African low-income settlements: a case study
}

\author{
B. Language, S. J. Piketh, B. Wernecke \& R. Burger \\ Unit for Environmental Sciences and Management, \\ North-West University, South Africa
}

\begin{abstract}
Residential solid fuel combustion emission within low-income communities result in increased negative health impacts within these settlements. The Highveld is considered to be the industrial epicentre of South Africa as it houses 11 of the 13 coal-fired power stations situated within the country's borders. The availability of low-cost coal within the area makes it the fuel of choice for heating and cooking purposes within low-income settlements. As a result residents of these settlements are continuously exposed to high concentrations of air pollutants. A paucity in data, on the impact of residential solid fuel combustion, exists since research is mainly focussed on industrial emission impacts. This paper aims to accurately quantify and characterise the mass concentrations of particulate matter experienced within both the indoor $\left(\mathrm{PM}_{4}\right)$ and ambient $\left(\mathrm{PM}_{10}, \mathrm{PM}_{2.5}\right)$ environments of KwaDela, a low-income settlement located on the South African Highveld. Furthermore, an attempt was made to link the indoor and ambient particulate mass concentrations, identify diurnal patterns and seasonal variations. KwaDela experiences high levels of particulate pollution, within both the indoor and ambient environment, as a result of domestic solid fuel combustion. Energy use varies seasonally with higher consumption of solid fuels during the winter leading to increased particulate loading. The concentrations of respirable particulate concentrations within the indoor environment are significantly higher than $\mathrm{PM}_{10}$ and $\mathrm{PM}_{2.5}$ experienced in the ambient environment. This indicates that the effect of respirable particulate matter, associated with solid fuel combustion in the indoor environment, has been underrepresented and thus its effect on health underreported.
\end{abstract}

Keywords: indoor, ambient, air quality, particulate matter, low-income settlements, South Africa. 


\section{Introduction}

Research has mainly focused on ambient air pollution; however, in recent years this focus has shifted toward indoor air pollution studies. Studies have identified significantly higher concentrations of pollutants within indoor environments than previously thought [1]. More recently, however, studies have shown that pollutants in the ambient environment are also found within the indoor environment, every so often even at higher concentrations [2]. It is estimated that around 2.8 to 3 billion people rely on solid fuel combustion as a primary energy source which leads to increased levels of air pollution associated with household emissions [3]. This is especially true within developing countries where solid fuels undergo incomplete combustion within poorly constructed or makeshift stoves [4]. Particulate pollution originating from the incomplete combustion of solid fuels have negative health effect on those that are exposed to it [5]. The 2010 Global Burden of Disease estimates that the use of solid fuels resulted in an estimated 3.5 (uncertainty: 2.7, 4.5) million premature deaths in 2010, while the World Health Organisation (WHO) estimates 4.3 million premature deaths [3].

South Africa is characterised as a developing country and is home to numerous middle- to low-income settlements. These settlements were built as low-cost housing developments, by the South African Government based programmes known as the Reconstruction and Development Program (RDP). Most of these settlements were developed in existing informal 'townships' on urban boundaries and in rural areas. During the past decade many issues surrounding the RDP developments have arisen, these include: i) RDP developments do not address the problems surrounding poverty in these areas; and ii) the structures and infrastructures are of poor quality and require increasing maintenance [6]. A significant proportion of middle- to low-income settlements, which are predominantly made up of RDP houses tend to implement the use of residential solid fuel combustion as a primary source of energy due to increased levels of poverty and the high cost of electricity. How does the use of solid fuels within the settlement impact on the residents of these settlements?

This paper aims to accurately quantify the particulate concentrations experienced within a typical South African low-income settlement prone to the residential combustion of solid fuels (coal). This is achieved by answering the following research questions i) what is the primary energy source used in the settlement; ii) what are the ambient and indoor particulate concentrations within the settlement; iii) what is the relationship between ambient, indoor, and personal particulate concentration measurements; and iv) what are the associated diurnal patterns and seasonal variations of ambient and indoor particulate concentrations.

\section{Materials and methods}

\subsection{Study area description and site selection}

KwaDela $\left(26^{\circ} 27^{\prime} 47.53^{\prime \prime} \mathrm{S} ; 2^{\circ} 39^{\prime} 51.73^{\prime \prime} \mathrm{E}\right)$ is situated between Ermelo and Bethal, in the Gert Sibande District Municipality, which is approximately $200 \mathrm{~km}$ south- 
east of Johannesburg (Figure 1). The settlement lies within the appropriately termed Highveld Priority Area, which represents an area of particularly high ambient air pollution levels. It is primarily directly surrounded by natural grasslands and land used for commercial cultivation, thus to a certain degree it is isolated from large industrial activities. Sources that potentially contribute the state of ambient air quality within the settlement includes traffic from the N17 route as well as within the settlement itself, the railway line, waste burning within the settlement, and residential solid fuel combustion.

According to the 2011 South African National Census data the settlement has a total population of 3777 people occupying 984 households. Each household has an average of 4.1 inhabitants. KwaDela is classified as a low-income settlement as the mean monthly income per household is below R1500, which is equivalent to approximately $\$ 100$.

\subsection{Experimental design}

Sampling was conducted over a period of two years, consisting of two winter and two summer sampling campaigns. The winter campaigns were performed during the months of July to September, while the summer campaigns were performed during February to May. Each sampling campaign stretched approximately 10 to 12 weeks. The winter sampling campaigns represent the worst case scenario and the summer the best. The reasons for this is i) winter have improved dispersion potential due to existing high pressures, and ii) less burning is expected during summer due to higher ambient temperatures.

Ambient monitoring was done by utilising a mobile monitoring station. The monitoring station was situated in an open area close to the centre of the settlement (Figure 1). This was done as to get the best possible representation of the ambient air quality within the settlement, without influences from external sources. The monitoring station housed various instruments, continuously monitoring both gaseous and particulate pollution as well as meteorological parameter (temperature, pressure, humidity, rainfall, wind speed and direction). Among these instruments were the MetOne BAM 1020 (measuring $\mathrm{PM}_{10}$ ) and the MetOne E-BAM (measuring $\mathrm{PM}_{2.5}$ ).

A total of 207 households, thus $21 \%$ of the settlement, were subjected to a structured interviewer-questionnaire. This provide information related to household energy use and perceived quality of life. The interviewed households complied with the following minimum requirements: i) they were RDP programme houses consisting of two bedrooms, a living room, and a kitchen area; ii) there were no additional extensions to the original house; and iii) informed consent was given by participants.

Indoor and personal sampling, related to the respirable fraction of particulate matter $\left(\mathrm{PM}_{4}\right)$, was conducted within twenty randomly selected households (from those that participated in the structured interviewer-questionnaires). A network of photometric light scattering instruments (DustTrak 8520 (x4); DustTrak II 8530 (x4), and SidePak AM510 (x8)) were deployed within the selected houses. The DustTrak's were placed within the indoor kitchen area (area of solid fuel combustion) or as close to the area as possible. The SidePak instruments were 


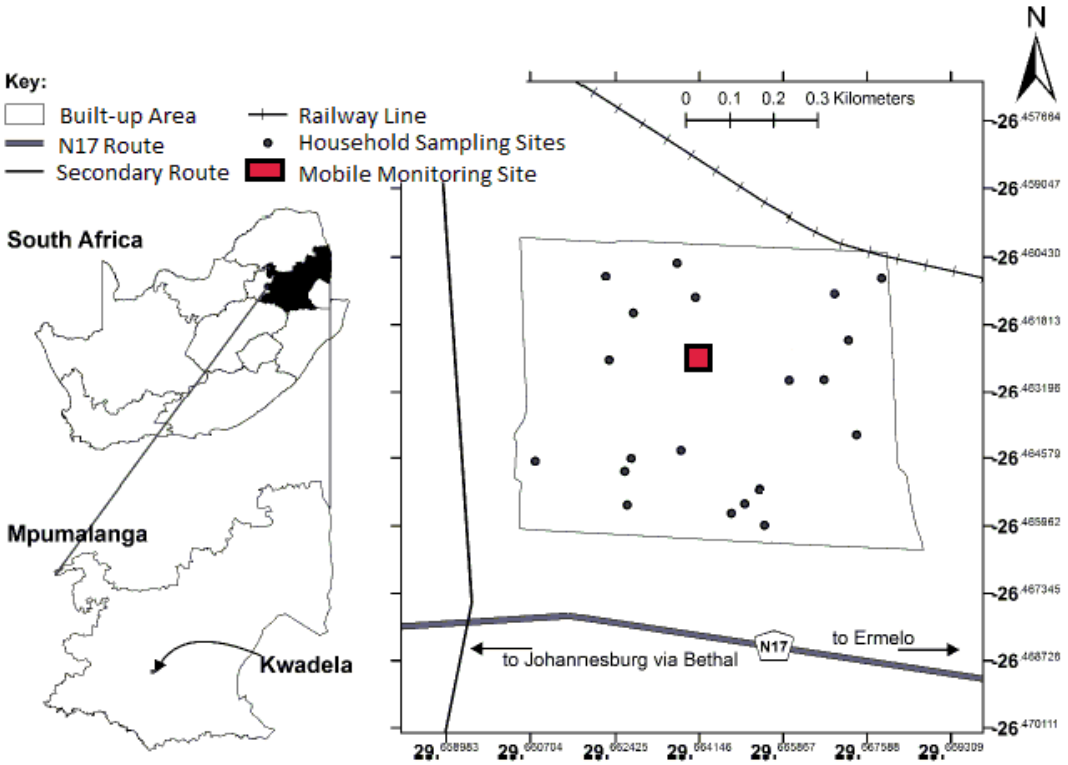

Figure 1: Map of KwaDela low-income settlement in Mpumalanga, South Africa. The spatial distribution of the ambient mobile monitoring station and households utilised for indoor and personal sampling are also indicated.

personally carried by one member of the household during the day, thus it includes particulate concentrations from ambient and indoor sources. These instruments were fitted with 10-mm Nylon Dorr-Oliver Cyclone inlets and sampled at a flow rate of 1.7 L.min ${ }^{-1}( \pm 5 \%)$. The cyclone provided the $4 \mu \mathrm{m}$ cut size. The instruments were rotated every two weeks. Additionally, temperature iButtons were located in each room within the house, at a distance on $10 \mathrm{~cm}$ from the stove chimney as well as externally (on the south-facing wall). This was done so as to provide data on the temperature dynamics of the houses including the burning cycles. The above mentioned methodological approach was approved by NorthWest University ethical committee.

\subsection{Data collection and analysis}

The mobile monitoring station recorded data at 1-min averaging intervals, while the photometric instruments were set to 5-min averaging intervals. Site visits were conducted on a weekly basis to collect data and perform general maintenance (filter, zero and flow checks as per manufacturer's instructions) on the instruments. The data were combined into a single dataset, for each season, containing all relevant parameters. It is important to note that a photometric calibration factor (PCF) of 0.715 was applied to the $\mathrm{PM}_{4}$ measurements. This PCF was obtained by comparing continuous and gravimetric $\mathrm{PM}_{4}$ mass concentrations sampled within 
the indoor solid fuel (coal) burning environment of a low-income settlement (KwaZamokuhle) on the South African Highveld.

The datasets underwent general descriptive statistical- and regression analyses. The regression analyses provided the correlation associated with the particulate concentrations. Additionally the datasets were averaged hourly and plotted on simple time-series as to obtain the diurnal patterns associated with each season. Finally, the daily averages for each season were computed and compared to the WHO standards set for particulate matter. This was done for a two week case study period during winter 2013 and summer 2014.

\section{Results and discussion}

\subsection{Study population}

The majority (97.10\%) of households have access to electricity, however, there is still a high rate of solid fuel use - coal (75.36\%) and wood (63.28\%). Note that $40.57 \%$ of households use a combination of these fuels. Wood is used in smaller quantities in all houses as it serves as an ignition source for coal. Household energy use and consumption varies between the sampling seasons. Coal is primarily used for cooking and heating purposes during winter months. Burning occurs at specific times, namely i) 4 to $6 \mathrm{AM}$; ii) 6 to $9 \mathrm{AM}$; iii) 4 to $6 \mathrm{PM}$; and iv) 6 to 9 PM. Cast-iron stoves are used by $61 \%$ of households, followed by welded stoves $(11.5 \%)$.

\subsection{Household PM measurements and relationships}

Residents are exposed to high particulate levels associated with domestic solid fuel combustion. Particulate concentrations, ambient and indoor, show significant changes between winter- and summer sampling campaigns (Table 1). The mean ambient levels (Table 1) vary significantly between seasons. Ambient $\mathrm{PM}_{10}$ concentrations are $102.1 \pm 76.96$ and $99.29 \pm 61.39\left(\mu \mathrm{g} . \mathrm{m}^{-3}\right)$ respectively, and summer concentrations are $50.43 \pm 29.59$ and $66.03 \pm 25.86\left(\mu \mathrm{g} . \mathrm{m}^{-3}\right) . \quad \mathrm{PM}_{2.5}$ concentrations show less seasonality compared to $\mathrm{PM}_{10}$. Finer aerosols were lower than the coarse fraction by a factor of 4 to 5 (winters) and 2 to 3 (summers). From this point forwards, ambient particulate concentrations will be represented by $\mathrm{PM}_{2.5}$ and indoor by $\mathrm{PM}_{4}$. Indoor particulate concentrations are higher than ambient by factor of 7 in the winter. Summer particulate concentrations (indoor and ambient) are more comparable. Personal exposure to particulate matter is closely related to the particulate concentrations within the indoor- than ambient environment.

A summary of the correlation between ambient, indoor and personal PM mass concentrations measurements are given in Table 2. The regression analysis indicated a moderate correlation between winter 2014 ambient $\mathrm{PM}_{2.5}$ and personal $\mathrm{PM}_{4}$ concentrations as well as indoor and personal $\mathrm{PM}_{4}\left(\mathrm{R}^{2}=0.32\right.$ and 0.34 respectively). There is a moderately strong correlation $\left(\mathrm{R}^{2}=0.43\right)$ between ambient $\mathrm{PM}_{2.5}$ and personal $\mathrm{PM}_{4}$ measurements. The strongest correlation $\left(\mathrm{R}^{2}=\right.$ 0.93 ) exists between indoor and personal $\mathrm{PM}_{4}$ during summer 2015. 
Table 1: Summary of the descriptive statistics associated with the seasonally time-integrated (1-min) ambient, indoor and personal (5-min) particulate measurements.

\begin{tabular}{lllllllll}
\hline & $\begin{array}{l}\text { Ambient } \\
\mathbf{P M}_{\mathbf{1 0}}\end{array}$ & $\begin{array}{l}\text { Ambient } \\
\mathbf{P M}_{2.5}\end{array}$ & $\begin{array}{l}\text { Indoor } \\
\mathbf{P M}_{\mathbf{4}}\end{array}$ & $\begin{array}{l}\text { Personal } \\
\mathbf{P M}_{\mathbf{4}}\end{array}$ & $\begin{array}{l}\text { Ambient } \\
\mathbf{P M}_{\mathbf{1 0}}\end{array}$ & $\begin{array}{l}\text { Ambient } \\
\mathbf{P M}_{2.5}\end{array}$ & $\begin{array}{l}\text { Indoor } \\
\mathbf{P M}_{\mathbf{4}}\end{array}$ & $\begin{array}{l}\text { Personal } \\
\mathbf{P M}_{\mathbf{4}}\end{array}$ \\
\hline Mean & 102.10 & 23.96 & 190.80 & 109.60 & 50.43 & 21.61 & 56.53 & 87.07 \\
SD & 76.96 & 11.39 & 626.26 & 382.71 & 29.59 & 12.31 & 184.51 & 255.55 \\
Max & 843.00 & 206.00 & 14680.00 & 5131.00 & 325.20 & 119.00 & 1288.00 & 5909.00 \\
Min & 4.47 & 1.73 & 0.07 & 0.01 & 6.71 & 7.73 & 3.58 & 0.01 \\
Median & 86.13 & 21.38 & 58.18 & 46.31 & 42.64 & 19.03 & 19.30 & 41.47 \\
$\boldsymbol{N}$ & 1420 & 1901 & 2648 & 438 & 2241 & 1368 & 2414 & 49.00 \\
\hline \multirow{2}{*}{ Mean } & 99.29 & 27.89 & 175.60 & 61.77 & 66.03 & 18.64 & 117.70 & 84.84 \\
SD & 61.36 & 22.20 & 518.16 & 76.21 & 25.86 & 9.30 & 259.42 & 127.33 \\
Max & 447.40 & 207.50 & 14110.00 & 469.20 & 174.30 & 153.20 & 2621.00 & 525.60 \\
Min & 21.85 & 1.79 & 0.09 & 10.81 & 20.55 & 0.07 & 0.26 & 2.15 \\
Median & 88.94 & 22.51 & 55.95 & 40.60 & 60.25 & 16.73 & 47.07 & 37.45 \\
$\boldsymbol{N}$ & 903 & 1660 & 1179 & 39 & 2076 & 5148 & 5270 & 105 \\
\hline
\end{tabular}

Table 2: $\quad$ Summary of the regression analyses between ambient, indoor, and personal particulate measurements.

\begin{tabular}{|c|c|c|c|c|}
\hline & $\mathbf{R}^{2}$ & Standard Error & $\mathbf{R}^{2}$ & Standard Error \\
\hline & Winter 2013 & & Summer 2014 & \\
\hline Ambient $\mathbf{P M}_{2.5}$ / Indoor $\mathbf{P M}_{4}$ & 0.0098 & 0.1689 & 0.0002 & 0.1636 \\
\hline Ambient $\mathbf{P M}_{10} /$ Indoor $\mathbf{P M}_{4}$ & 0.0325 & 0.4224 & 0.0020 & 0.2020 \\
\hline Ambient $\mathbf{P M}_{2.5}$ / Personal $\mathbf{P M}_{4}$ & 0.0064 & 1.764 & 0.4346 & 1.113 \\
\hline Ambient $\mathbf{P M}_{10}$ / Personal $\mathbf{P M}_{4}$ & 0.0013 & 0.2044 & 0.0638 & 0.8441 \\
\hline \multirow[t]{2}{*}{ Indoor $\mathbf{P M}_{4} /$ Personal $\mathbf{P M}_{4}$} & 0.0324 & 0.0302 & 0.0155 & 0.9100 \\
\hline & Winter 2014 & & Summer 2015 & \\
\hline Ambient $\mathbf{P M}_{2.5}$ / Indoor $\mathbf{P M}_{4}$ & 0.0101 & 0.5860 & 0.0069 & 0.8348 \\
\hline Ambient $\mathbf{P M}_{10} /$ Indoor $\mathbf{P M}_{4}$ & 0.0149 & 0.2776 & 0.0178 & 0.1676 \\
\hline Ambient $\mathbf{P M}_{2.5}$ / Personal $\mathbf{P M}_{4}$ & 0.3249 & 0.571 & 0.0040 & 2.023 \\
\hline Ambient $\mathbf{P M}_{10}$ / Personal $\mathbf{P M}_{4}$ & 0.0266 & 0.2424 & 0.1334 & 0.3434 \\
\hline Indoor $\mathrm{PM}_{4}$ / Personal $\mathrm{PM}_{4}$ & 0.3417 & 0.1207 & 0.9358 & 0.0101 \\
\hline
\end{tabular}




\subsection{Diurnal patterns and season variations}

The diurnal pattern of hourly averaged particulate concentrations associated with each season (Figure 2) is very distinctive. Winters are marked with lower mean ambient temperatures ranging between 4 and $20^{\circ} \mathrm{C}$, while individual measurements reach sub-zero during the evenings. Summer averages range from $10-28^{\circ} \mathrm{C}$. The peaks in particulate concentrations, for both the ambient and indoor environments, correspond with lower ambient temperatures. Winter particulate concentrations peak for an extended time ( 4-6 hours), compared to summer ( $\sim-4$ hours). The indoor concentrations are substantially higher during winter due to i) the majority of the residential solid fuel combustion occurs indoors; and ii) the lack of ventilation resulting from closed doors and windows keeping the heat inside. It is important to note that the peaks in the indoor environment corresponds directly to the increased temperatures measured at the stoves. These

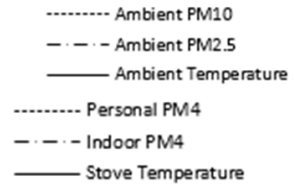

Winter 2013 Ambient and Personal

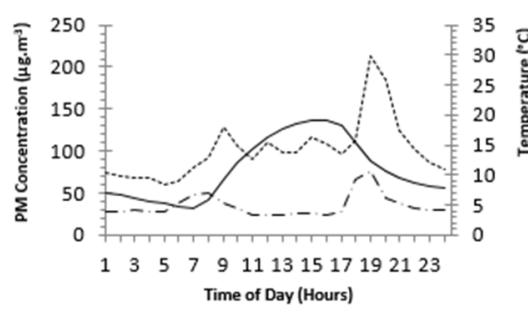

(a)
Summer 2014 Ambient Indoor and Personal

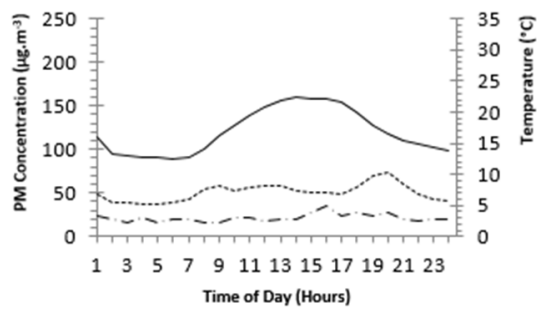

(c)
Winter 2013 Indoor

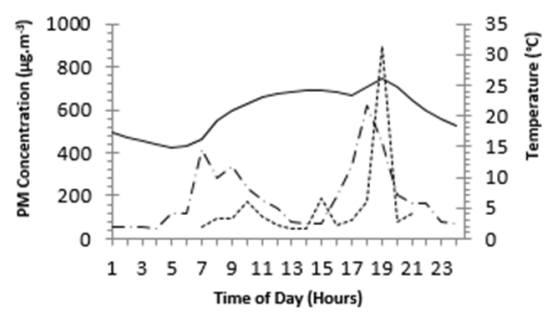

(b)
Summer 2014

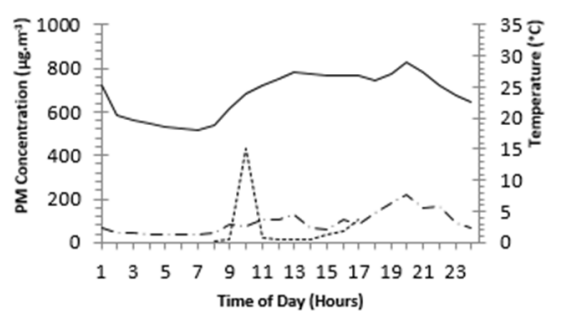

(d)

Figure 2: Diurnal patterns for hourly averaged ambient $\left(\mathrm{PM}_{10}\right.$ and $\left.\mathrm{PM}_{2.5}\right)$, indoor $\left(\mathrm{PM}_{4}\right)$ and personal $\left(\mathrm{PM}_{4}\right)$ particulate concentrations $\left(\mu \mathrm{g} \cdot \mathrm{m}^{-3}\right)$. Categorised by season: winter 2013 (a) $\mathrm{PM}_{10}$ and $\mathrm{PM}_{2.5}$, (b) $\mathrm{PM}_{4}$, summer 2014 (c) $\mathrm{PM}_{10}$ and $\mathrm{PM}_{2.5}$ and (d) $\mathrm{PM}_{4}$. 
trends are considered to be a signature trend for low level residential solid fuel burning activities, thus the particulate concentrations measured in both the ambient and indoor environment are directly influenced by the combustion of solid fuel within the residential area.

\subsection{Case studies}

A two week period during winter 2013 (Figure 3(a) and (b)) and summer 2014 (Figure 4(a) and (b)) was randomly selected as case study. It is clear that there is a larger variability in both particulate concentrations and temperatures experienced during the two-week period of winter 2013 than summer 2014. The mean daily ambient temperatures range from $4-15^{\circ} \mathrm{C}$ (winter) and $14-20^{\circ} \mathrm{C}$ (summer). As previously mentioned increased combustion leads to increased level of respirable

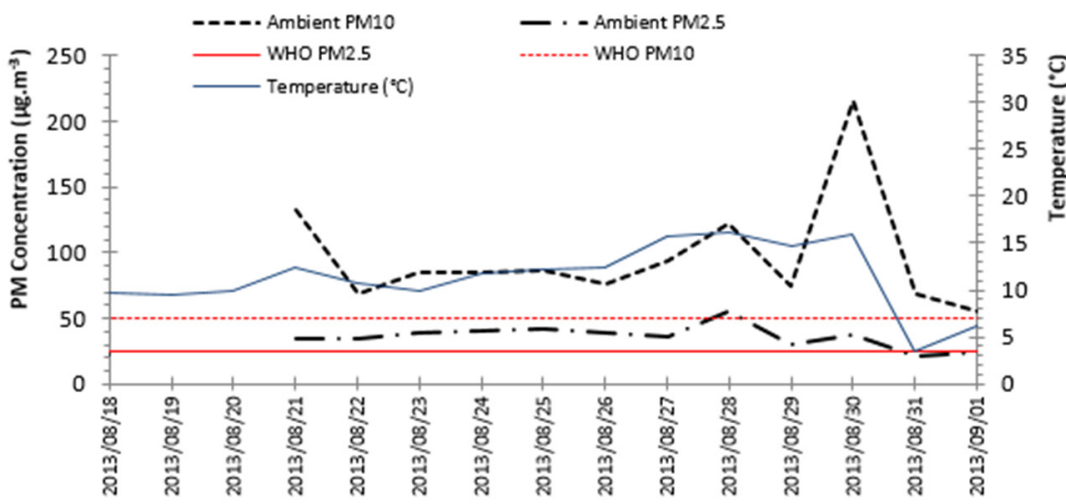

(a)

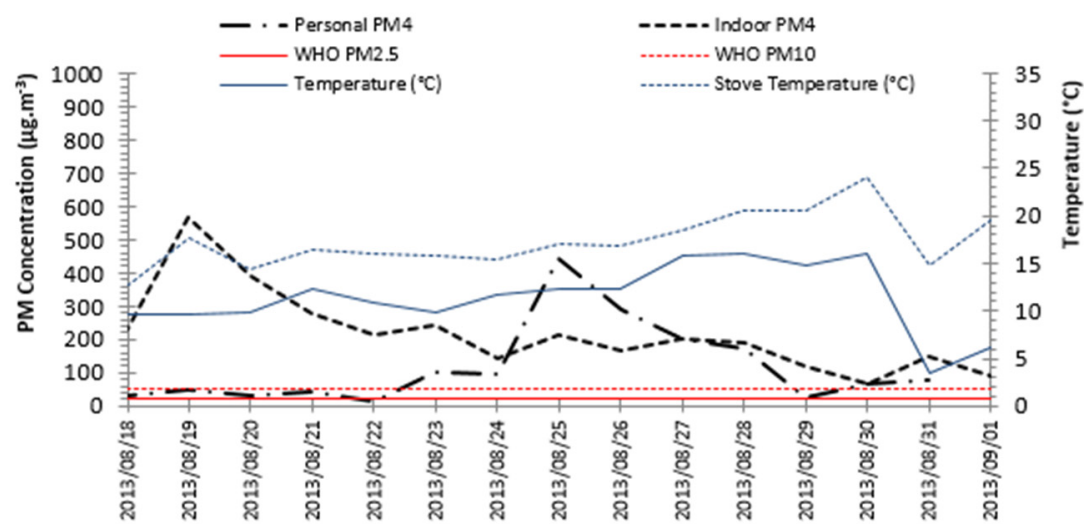

(b)

Figure 3: Time-series graphs of the daily PM averages measured over a two week period during winter 2013 for (a) ambient $\mathrm{PM}_{10}$ and $\mathrm{PM}_{2.5}$ as well as (b) indoor and personal $\mathrm{PM}_{4}$. 
particulate concentrations within the indoor environment which can also be seen in the ambient concentrations, however, August 30th experiences a peak in ambient $\mathrm{PM}_{10}$ and $\mathrm{PM}_{2.5}$ whereas the indoor $\mathrm{PM}_{4}$ is much lower than expected.

The ambient $\mathrm{PM}_{10}$ levels exceeds the $50 \mu \mathrm{g} . \mathrm{m}^{-3}$ WHO 24-hr $\mathrm{PM}_{10}$ standard for the entire two-week winter period. This is also the case for the $\mathrm{PM}_{2.5}$ levels compared to the $25 \mu \mathrm{g} . \mathrm{m}^{-3} \mathrm{WHO} 24-\mathrm{hr} \mathrm{PM}_{2.5}$ standard, except for the August 31st. The ambient $\mathrm{PM}_{10}$ levels exceeds the $50 \mu \mathrm{g} \cdot \mathrm{m}^{-3}$ WHO 24-hr $\mathrm{PM}_{10}$ standard eight times during the two-week summer period, while $\mathrm{PM}_{2.5}$ exceeds the $25 \mu \mathrm{g} . \mathrm{m}^{-3}$ WHO 24-hr $\mathrm{PM}_{2.5}$ standard five times during this time. It is clear that particulate measurements will exceed the South African National Ambient Air Quality Standards, as they are higher than those set by the WHO. South Africa has no set

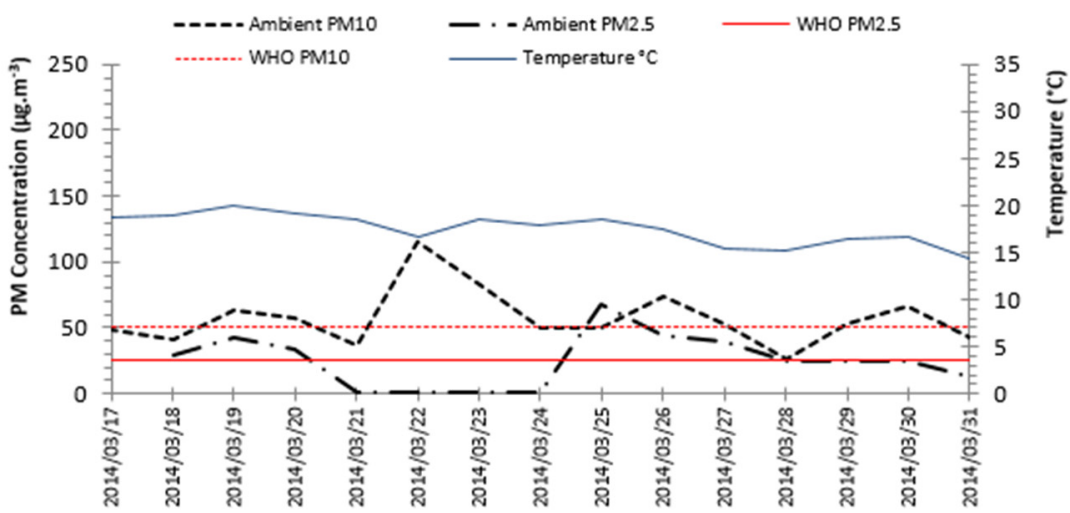

(a)

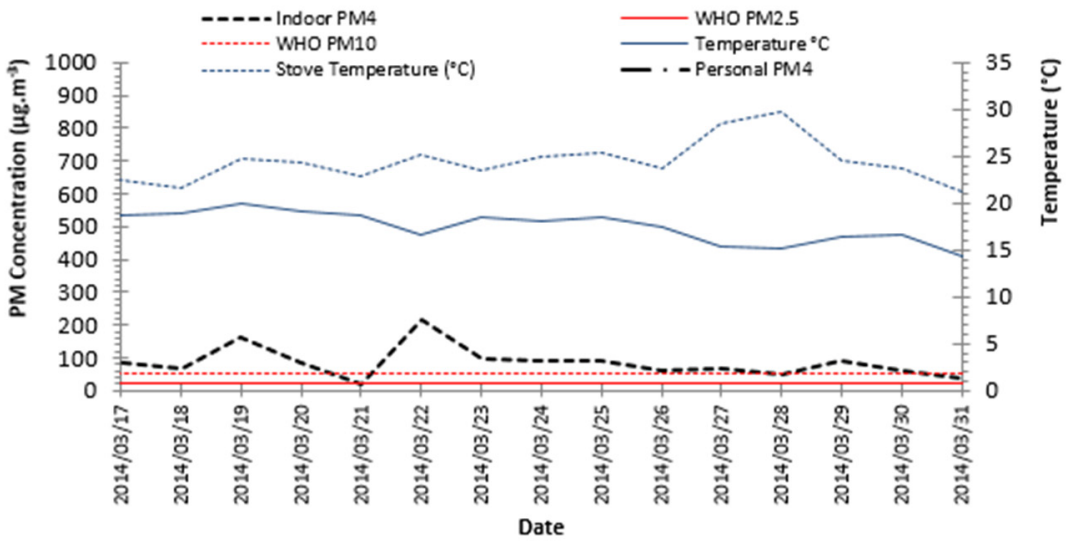

(b)

Figure 4: Time-series graphs of the daily PM averages measured over a two week period during summer 2014 for (a) ambient $\mathrm{PM}_{10}$ and $\mathrm{PM}_{2.5}$ as well as (b) indoor and personal $\mathrm{PM}_{4}$. 
standard for indoor particulate pollution, thus the WHO 24-hr $\mathrm{PM}_{10}$ and $\mathrm{PM}_{2.5}$ standards were used as reference. The daily indoor $\mathrm{PM}_{4}$ concentrations constantly exceed these standards, during both seasons.

\section{Conclusion}

This study was designed to evaluate particulate matter associated with residential solid fuel combustion, within a typical low-income settlement in South Africa. The primary energy source used in domestic solid fuel combustion is coal long with small quantities of wood. Residents are exposed to increasingly high concentrations of respirable particulate matter within the indoor environment, which is higher than ambient concentrations by a factor of 7 during winter, while summer concentrations are more comparable. Personal particulate exposure is closely related to indoor particulate concentrations. Diurnal patterns and seasonal variation are distinctly associated with low-level residential solid fuel burning activities, with combustion times ranging from 2-4 hours in the summer between 4 and 6 hours in the winter. This paper is the first to represent data on the particulate concentrations experienced (indoor, ambient and personal), as a result of domestic solid fuel combustion, within a South African low-income settlement.

\section{References}

[1] Myers, I. \& Maynard, R.L. Polluted air--outdoors and indoors. Occup. Med. (Lond). 55(6): 432-8, 2005.

[2] Chen, B.H., Hong, C.J., Pandey, M.R., \& Smith, K.R. Indoor air pollution in developing countries. World Health Stat. Q. 43(3): 127-138, 1990.

[3] Bruce, N., Pope, D., Rehfuess, E., Balakrishnan, K., Adair-Rohani, H., \& Dora, C. WHO indoor air quality guidelines on household fuel combustion: Strategy implications of new evidence on interventions and exposure-risk functions. Atmos. Environ. Elsevier Ltd. 106: 451-457, 2015.

[4] Bruce, N., Perez-Padilla, R., \& Albalak, R. Indoor air pollution in developing countries: a major environmental and public health challenge. Bull. World Health Organ. 78(9): 1078-1092, 2000.

[5] Bruce, N., Perez-Padilla, R., \& Albalak, R. The health effects of indoor air pollution exposure in developing countries. Geneva World Heal. Organ. Rep. WHO/SDE/OEH/02.05. :1-40, 2002.

[6] Goebel, A. Sustainable urban development? Low-cost housing challenges in South Africa. Habitat Int. 31(3-4): 291-302, 2007. 